\title{
ENSAIO DA QUALIDADE DOS PARAFUSOS ATRAVÉS DE RESISTÊNCIA AO TORQUE
}

Michelle Silva Lima - michelleisislima@gmail.com Rayane Fontanella Santiago - rayfsantiago@ hotmail.com João Pedro Maciel Trajano - j.pedromec@ hotmail.com Leonardo Chahim Pereira - chahim@outlook.com.br Tiago Bittencourt Nazaré - tiago@unis.edu.br

RESUMO: Este artigo busca analisar a qualidade dos parafusos através do Ensaio prático de Resistência ao Torque. Considerando a acirrada competitividade no atual cenário industrial, exige-se que as organizações busquem excessivamente melhorias na qualidade de seus produtos, tanto no processo de gestão, como nos processos operacionais a fim de garantirem sua sobrevivência no mercado, com um produto que atenda às expectativas do seu cliente. Para o estudo, foram realizados testes e utilizados materiais, tais como: 10 (dez) parafusos com cabeça sextavada de aço 1020 com 3/8" (três oitavos) de diâmetro e 50 (cinquenta) milímetros de comprimento e 10 (dez) parafusos com cabeça sextavada de aço $1020 \mathrm{com}$ 1/2" (um meio) de diâmetro e 50 (cinquenta) milímetros de comprimento, fabricados respectivamente por Belenus e Jomarca. Com os dados obtidos, foram verificados os gráficos de torque e distorção com base nos resultados dos ensaios. Ofabricante Belenus obteve melhor desempenho baseado nos dados adquiridos e tabela de torque dos parafusos.

Palavras-chave: Resistência. Torque. Qualidade. Parafusos.

\section{INTRODUÇÃO}

A globalização veio para redefinir o significado de competitividade obrigando as organizações a se adaptarem, as que foram incapazes, ou se recusaram, a se adequar às novas tecnologias consequentemente tornaram-se arcaicas, e, como resultado tiveram um fim prematuro. Segundo Andrade e Amboni (2010), esta competitividade pode ser definida como a capacidade das empresas em desenvolverem e implantarem métodos, técnicas e estratégias concorrenciais, que lhe possibilitem fornecer produtos de qualidade a fim de garantir sua sobrevivência no mercado.

A qualidade é um termo que possui aplicações e significados diversos. Segundo Verri (2013), a qualidade são as totalidades de propriedades e características de um produto ou serviço, que lhes conferem aptidão de atender as aplicações e necessidades dos clientes.

Para se conhecer a qualidade de um material é necessário identificar os seus requisitos, aos quais muitas das vezes podem ser identificados através da especificação do projeto, dos requisitos legais e dos requisitos contratuais. Segundo Ueno (2017), assim, após reconhecer e definir os requisitos da qualidade de um produto, é necessário que se conheça o grau de atendimento a esse produto, e com base nisso, criou-se o conceito de Controle de Qualidade que é parte essencial para uma organização fornecer produtos adequados, que segundo o autor, deve ser baseado, principalmente, nas inspeções de materiais, onde serão realizados ensaios, possuindo como parâmetro a especificação do cliente e norma do produto.

Ensaios realizados nos materiais são empregados para várias finalidades, tais como: obtenção das propriedades dos materiais, verificação do projeto e do controle de qualidade para ter a certeza que o material atende aos requisitos estabelecidos pelas especificações. De acordo com Dowling (2017), fornecedores de materiais, usuários e organizações de pesquisa vêm 
trabalhando em conjunto para desenvolver os métodos de ensaios normatizados.

Conforme Estrela (2018), o ensaio de torção consiste em aplicar uma força no corpo de prova para induzir o movimento em torno de seu centro de massa e ao longo de seu eixo maior, que tem como objetivo quantificar o torque máximo suportado pelo material e o ângulo de deformação induzido. Segundo o autor, através desse ensaio também pode-se determinar o limite de escoamento à torção, o módulo de ruptura, o módulo de elasticidade e o ângulo máximo em torção, seus resultados dependerão da temperatura em que estão sendo executados, velocidade da aplicação do torque, matéria-prima, composição química e microestrutura do material.

De acordo com Estrela (2018), o torque é calculado mediante a multiplicação da intensidade da força pela distância ao eixo de rotação do corpo de prova, a fórmula para o cálculo é:

$$
\vec{T}=\vec{F} \cdot \vec{d}
$$

onde: T é torque, F é força aplicada e d é distância da força aplicada até o ponto fixo.

Conforme Ueno (2017), o trabalho com foco na obtenção de capital exige a dedicação total das empresas, as quais devem estar dispostas, e empenhadas, para melhorar o seu gerenciamento do controle da qualidade na execução das atividades e cumprimento das metas. Uma vez que as empresas estão cada vez mais competitivas, a qualidade é um fator primordial para fazer a diferença. Segundo revela o autor, para garantir que os seus produtos cheguem com qualidade ao consumidor, e com características compatíveis ao mercado, as empresas estão cada vez mais obrigadas a desenvolver os seus processos no que tange a qualidade em geral.

A metodologia do trabalho baseou-se em uma abordagem descritiva de natureza quantitativa, relacionada aos dados coletados para fins de pesquisa, e qualitativa no intuito de avaliar a qualidade dos parafusos. Foi também realizada uma pesquisa exploratória, tais como: livros e revistas, com objetivo de agregar valor à pesquisa e ao referencial teórico.

O presente estudo classifica-se como pesquisa bibliográfica e se concentra no estudo de um caso prático e específico. As pesquisas foram realizadas no período compreendido entre março de 2018 a maio de 2018.

\section{MATERIAIS E MÉTODOS}

Com o intuito de realizar uma avaliação da qualidade dos parafusos, foi aplicado o ensaio de resistência ao torque. Para este ensaio foram comprados 20 (vinte) parafusos de 02 (dois) fabricantes diferentes, sendo dez parafusos de cada fabricante. Os materiais e equipamentos utilizados para realização do ensaio foram: torquímetro da marca Gedore modelo L120, 01 (um) marcador industrial, 01 (uma) porca 3/8", 01 porca 1/2" e uma morsa para a fixação do parafuso. fórmulas:

Para construção dos gráficos foram realizados cálculos de acordo com as seguintes

$$
\begin{array}{r}
\text { Tensão }(\sigma)=\frac{F}{A} \\
\text { Área }(\mathrm{A})=\pi \mathrm{r}^{2} \\
\text { Torque }(\vec{T})=\vec{F} x \vec{d} \\
\text { Ângulo de distorção }(\phi)=
\end{array}
$$


$\mathrm{Lx} \Upsilon \min / \mathrm{c} 1$

Onde:

- $F$ é força e A é área;

- r é raio e $\pi$ é pi;

- Lé comprimento;

- Ymin é tensão deformação de cisalhamento;

- c1 é o diâmetro do parafuso.

Para a elaboração da análise de resistência ao torque, foram utilizadas as informações de acordo com a tabela 1. Essa tabela mostra torques para parafusos série polegada rosca normal UNC (N.m).

Tabela 1: Momentos Torçores (Torques)

\begin{tabular}{|c|c|c|c|c|}
\hline \multirow{2}{*}{$\begin{array}{l}\text { Rosca } \\
\text { Thread }\end{array}$} & \multicolumn{4}{|c|}{ Grau de resistência / Grado de resistencia / Grade designation } \\
\hline & 1 & 2 & 5 & 8 \\
\hline $1 / 4^{\prime \prime}-20$ & 4,8 & 7,8 & 12,1 & 17,0 \\
\hline $5 / 16^{\prime \prime}-18$ & 9,4 & 15,7 & 23,9 & 33,8 \\
\hline $3 / 8^{\prime \prime}-16$ & 16,2 & 26,8 & 41,5 & 58,4 \\
\hline $7 / 16^{\prime \prime}-14$ & 26 & 42 & 65 & 92 \\
\hline $1 / 2 "-13$ & 39 & 65 & 101 & 141 \\
\hline $9 / 16^{\prime \prime}-12$ & 56 & 92 & 143 & 201 \\
\hline $5 / 8^{\prime \prime}-11$ & 78 & 128 & 199 & 280 \\
\hline $3 / 4 "-10$ & 136 & 227 & 350 & 494 \\
\hline $7 / 8^{\prime \prime}-9$ & 218 & 218 & 562 & 793 \\
\hline $1 "-8$ & 327 & 327 & 841 & 1187 \\
\hline $1.1 / 8^{\prime \prime}-7$ & 464 & 464 & 1040 & 1685 \\
\hline $1.1 / 4 "-7$ & 649 & 649 & 1455 & 2359 \\
\hline $1.3 / 8 "-6$ & 854 & 854 & 1916 & 3106 \\
\hline $1.1 / 2 "-6$ & 1127 & 1127 & 2527 & 4097 \\
\hline
\end{tabular}

Para atingir força de aperto igual a $80 \%$ da carga de prova.

Fonte: www.ciser.com.br, 2018.

Conforme Tabela 1 de torques para parafusos série polegada rosca normal (N.m) verificamos que os parafusos dos fabricantes são de grau 2 (dois), ou seja, de aço de baixo carbono, sendo assim o torque dos parafusos de $1 / 2$ " e 3/8" de polegada são de 65 N.m e 27 N.m, respectivamente.

\section{QUALIDADE}

Segundo Junio et al (2015), o conceito de qualidade é conhecido há milênios, no entanto, só nos últimos anos ela surgiu como função de gerência, em que originalmente, tal função era 
voltada para a inspeção. Conforme o autor, nos dias atuais as atividades relacionadas com a qualidade se ampliaram e são consideradas primordiais para o sucesso estratégico, isso leva a uma percepção dinâmica e macro da qualidade.

Conforme a ISO 9001:2015, Sistema de Gestão da Qualidade, constitui no conjunto de diversos elementos incorporados à empresa para atender às normas da qualidade, objetivos da empresa e as exigências dos clientes. Logo, a qualidade seria o grau de perfeição de um procedimento, ofício ou produto oferecido por uma empresa, de forma que respeite as condições estabelecidas pelos clientes, e, é claro, pela ISO em questão.

\subsection{CONTROLE DE QUALIDADE}

De acordo com Cardoso (2009), o controle de qualidade apresenta aspectos peculiares e de grande importância que são aprendidos com a prática e a rotina das análises, além do desenvolvimento de novas metodologias, visando maior confiabilidade nos resultados. Conforme o autor, todas as atividades e ações devem ser planejadas sistematicamente, na razão do necessário ao uso funcional, para permitir a confiança apropriada de que um produto ou serviço satisfaça, ou atenda aos requisitos que são submetidos aos critérios de aceitação, ou rejeição.

Segundo Junior (2015), o conceito de controle da qualidade surge, pela primeira vez, no final da década de 1950 e vem com a premissa de que a qualidade deve ir além do produto. $\mathrm{O}$ controle da qualidade deve se iniciar na definição das políticas, padrões de processos e ações, pois esses procedimentos influenciarão no projeto do produto, e se estenderão na matéria-prima, no controle do processo de fabricação, ensaios, expedição e pessoas, desenvolvendo mais tarde o controle de qualidade total definido por Ishikawa. O Total Quality Control (controle da qualidade total) é um grupo de gestão da qualidade que procura sobrepujar o entendimento de qualidade aplicada ao processo ou produto. No TQC a qualidade deve ser compreendida como o sobrepujamento das expectativas de todas as partes interessadas (stakeholders), não apenas dos clientes.

Para Duarte (2015), o controle de qualidade total é mais técnico e mais abrangente, não se preocupa única e exclusivamente ao serviço, ou produto, mas sim, com todo o ciclo produtivo.

Já Seleme (2008) afirma que a detecção do defeito se procede por meio da inspeção, ensaios e testes no produto, anomalia associada a má performance do processo com capacidade insatisfatória. Esta detecção com base em instrumentos e na observação humana tem que ser precisa, permitindo rastreabilidade e previsão de tendências. A inspeção pode ser uma fonte de informação importante para a gestão da qualidade, para fins de análises e desempenho do produto.

\section{ENSAIOS DE RESISTÊNCIA AO TORQUE OU ENSAIO DE TORÇÃO}

O ensaio de torção realizado constituiu-se na aplicação de uma força contínua e controlada com o objetivo de colocar em teste os parafusos até a sua ruptura, para que fosse possível verificar se os mesmos estavam dentro do que havia sido especificado pelo fabricante.

Este ensaio tem como objetivo quantificar o torque máximo suportado pelo material e o ângulo de deformação induzido. Atráves do ensaio também pode-se determinar o limite de escoamento à torção, o módulo de ruptura, o módulo de elasticidade e o ângulo máximo em torção. Sabendo que os resultados dependerão da temperatura em que estão sendo executados, velocidade da aplicação do torque, matéria-prima, composição química e microestrutura do material. 
Segundo Dowling (2017), ensaios de torção são utilizados amplamente para avaliação do módulo de cisalhamento, limite de escoamento ao cisalhamento e outras propriedades dos materiais. Esses testes servem para diferenciar os testes de compressão e tração, analisando a distribuição não uniforme das tensões de deformações. Conforme o autor, nos casos de torção e flexão as deformações não uniformes e tensões formam uma situação em que a curva de tensãodeformação representativa do material não pode ser determinada diretamente a partir dos dados de teste.

Beer (2015) declara que os materiais dúcteis como o aço estrutural são caracterizados pela capacidade de escoar na temperatura ambiente. À medida que o corpo de prova é submetido a uma carga crescente, a deformação aumenta a uma taxa muito baixa inicialmente. Sendo assim, a parte inicial do diagrama tensão x deformação é uma linha reta, que corresponde a região elástica do material, ou seja, nesse ponto, o material consegue retornar ao tamanho original após sofrer uma leve deformação. No entanto, após alcançar um valor crítico de tensão, o corpo de prova sofre uma grande deformação com um aumento relativamente pequeno da carga.

Essa deformação é causada pelo deslizamento do material ao longo das superficies oblíquas e se deve às tensões de cisalhamento. Depois de alcançar um valor máximo de carga, o diâmetro de uma parte do corpo começa a diminuir em razão da instabilidade local. Segundo Beer (2015), depois de iniciado esse processo de estricção (diminuição da área), cargas mais baixas são suficientes para manter o corpo de prova alongado até que o material se rompa.

Figura 1: Curva tensão deformação de um aço com baixo teor de carbono

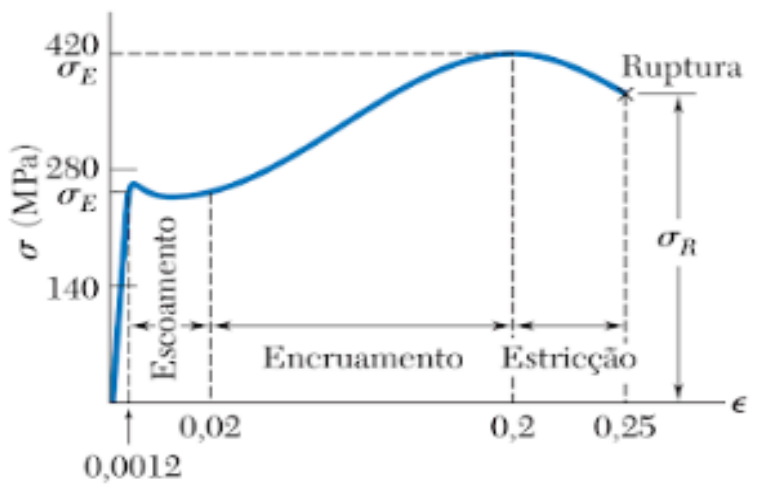

Fonte: Adaptado de Beer (2015) carbono.

A figura 1 mostra a curva de tensão deformação de um material dúctil com baixo teor de

\subsection{PARAFUSO SEXTAVADO}

Segundo Lano e Wallen (2013), os parafusos são conectores com ranhuras espiraladas, instalados com aplicação de torque, que por sua vez faz com que o parafuso penetre firmemente para dentro do material. As aplicações mais comuns incluem junção de elementos de marcenaria, montagem de equipamentos e outras aplicações em marcenaria de acabamento.

Ainda para Lano e Wallen (2013), os testes de resistência ao torque devem ser realizados conforme ABNT NBR 8158:2013 que descreve os procedimentos mínimos para ferragens e os 
critérios de aprovação no ensaio de resistência ao torque que se dá quando a porca do parafuso desliza manualmente ao longo de seu comprimento, após aplicação do torque tabelado durante 1 (um) minuto.

\section{ANÁLISES DE RESULTADOS}

Para realizar os testes, e obter os resultados para o projeto, foram utilizados alguns materiais, tais como: 10 (dez) parafusos com cabeça sextavada de aço $1020 \mathrm{com}$ 3/8" (três oitavos) de diâmetro e 50 (cinquenta) milímetros de comprimento de dois fabricantes diferentes, fabricantes A e B, 10 (dez) parafusos com cabeça sextavada de aço 1020 com 1/2" (um meio) de diâmetro e 50 (cinquenta) milímetros de comprimento de dois fabricantes A e B, 01 (um) torquímetro da marca Gedore modelo L120, 01 (um) marcador industrial, 01 porca 3/8", 01 porca $1 / 2$ " e uma morsa para a fixação do parafuso. Com base nestes ensaios, pode-se verificar se a qualidade dos parafusos realmente é confiável, com base única e exclusivamente neste ensaio de resistência ao torque.

O ensaio de resistência ao torque é muito importante para verificar se o material realmente suporta a tensão que poderá vir a ser exercida sobre ele. Para isso, foi realizado o ensaio em dois modelos de parafusos com diâmetros diferentes para observar se realmente os dados fornecidos pelo fabricante são reais, comparando os valores da Tabela 1 com os valores mostrados pelo torquímetro no momento da realização do ensaio de torque, ou se os parafusos possuiam alguma divergência nos valores, para mais ou para menos durante o ensaio de torção. Nos ensaios realizados pode-se observar o limite de proporcionalidade, o escoamento, o momento máximo e o momento de ruptura. As figuras 2 e 3 mostram os gráficos de torque e distorção nos parafusos ensaiados, lembrando que as curvas foram geradas para cada modelo de parafuso dos dois fabricantes, pois os resultados foram semelhantes.

Figura 2: Ensaio de Resistência ao Torque - BELENUS 3/8”

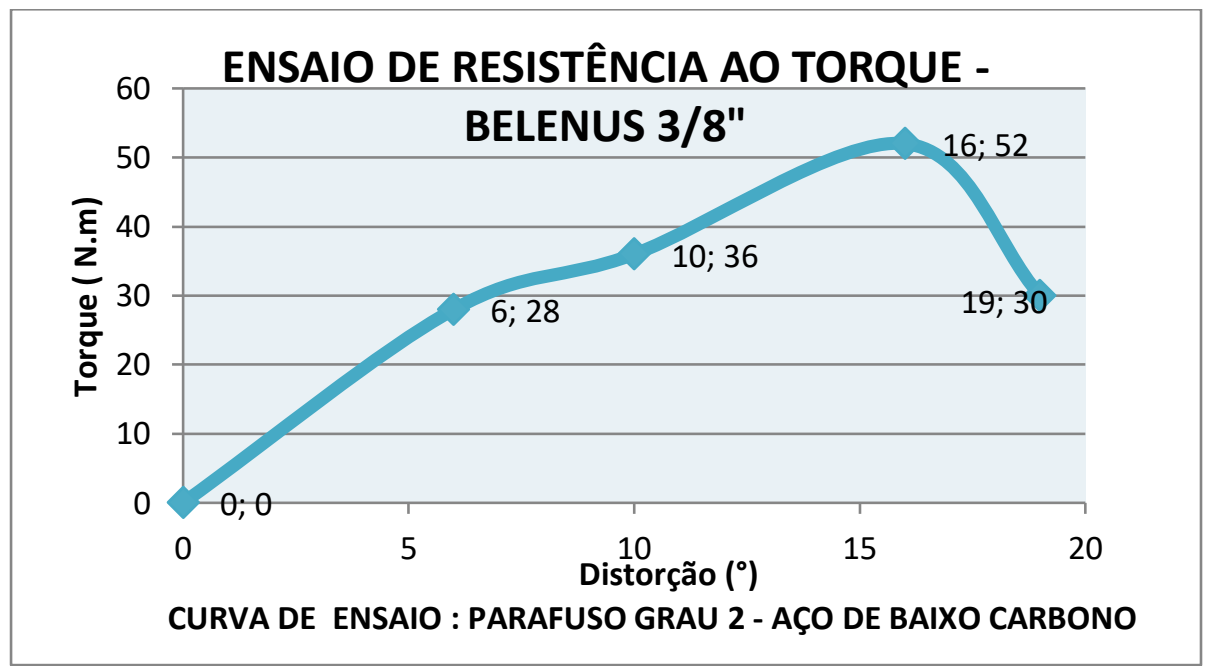

Fonte: Próprio autor (2018)

Conforme a figura 2, com o ensaio de resistência ao torque, nos parafusos sextavado de $3 / 8$ " da BELENUS foi encontrado torques de 28 N.m, enquanto que o especificado pela Tabela 1 
de torques para parafusos série polegada, rosca normal, é de 27 N.m. Portanto, os valores ficaram dentro da faixa de tolerância do torquimetro da Gedore que é de 3\%, conforme dados do próprio fabricante.

Figura 3: Ensaio de Resistência ao Torque - JOMARCA 3/8"

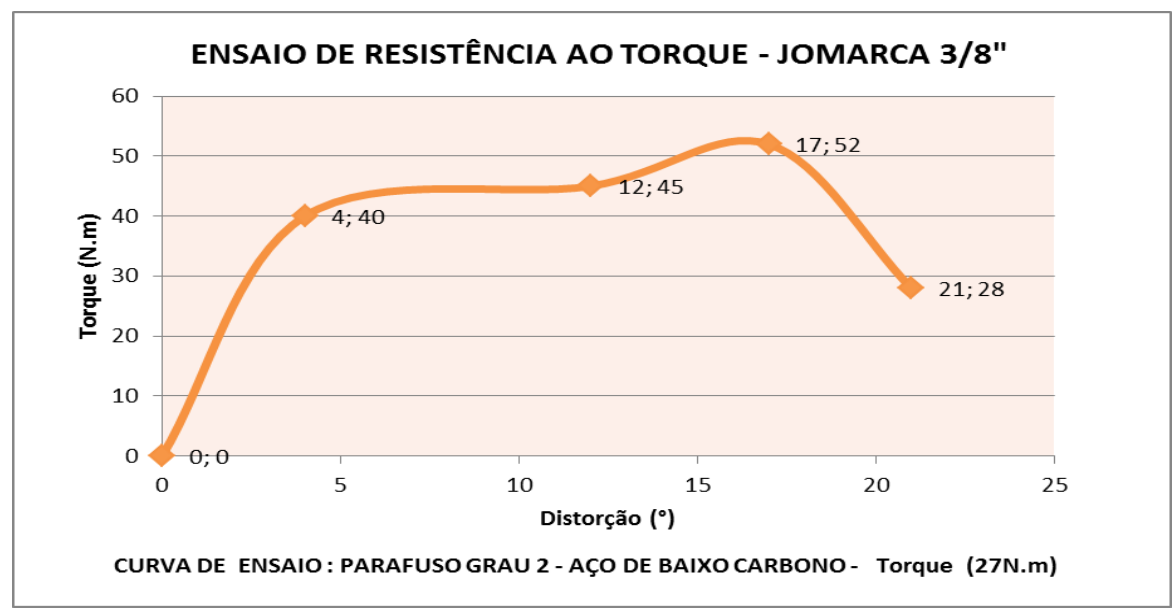

Fonte: Próprio autor (2018)

Conforme a figura 3 , com o ensaio de resistência ao torque, nos parafusos sextavado de 3/8" da JOMARCA foram encontrados torques de $40 \mathrm{~N} . \mathrm{m}$, enquanto que o especificado pela Tabela 1 de torques para parafusos série polegada rosca normal é de 27 N.m. Portanto, os valores não ficaram dentro da faixa de tolerância do torquimetro da Gedore que é de $3 \%$. Estes fatores podem ser resultados de algum procedimento externo que realizaram no material, seja um processo de caldeiraria, ou outro processo de usinagem para alterar a qualidade do material.

Figura 4: Ensaio de Resisência ao Torque - BELENUS 1/2”

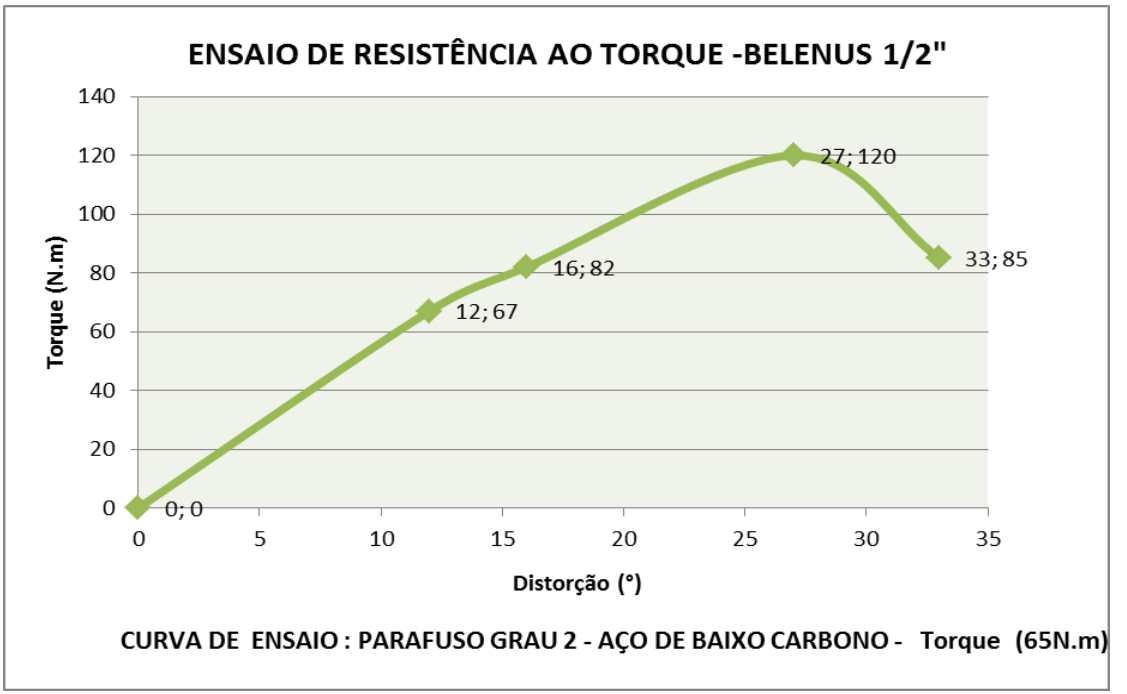


Nos parafusos sextavado de $1 / 2$ " da BELENUS foi encontrado torque de 67 N.m, enquanto que o especificado pela Tabela 1 de torques para parafusos série polegada, rosca normal, é de 65 N.m. Portanto, os valores ficaram dentro da faixa de tolerância do torquimetro da Gedore que é de $3 \%$, conforme dados do próprio fabricante.

Figura 5: Ensaio de Resisência ao Torque - JOMARCA 1/2”

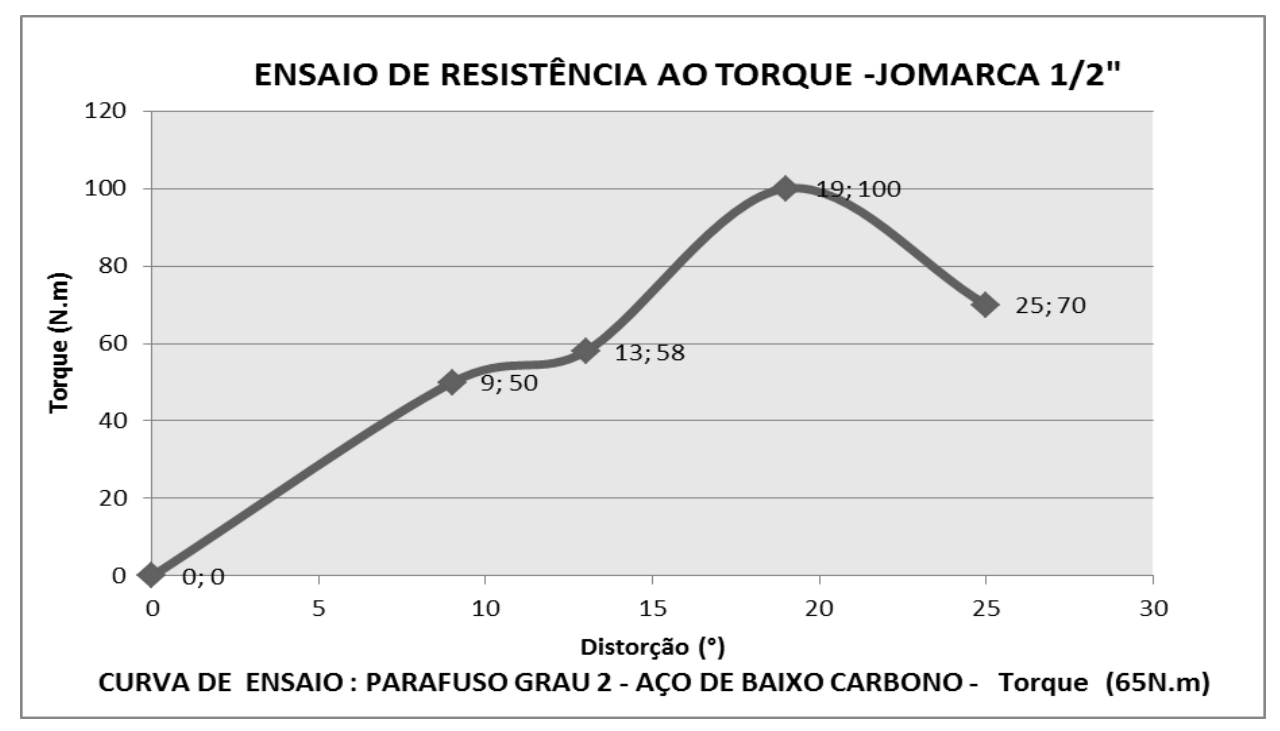

Fonte: Próprio autor (2018)

Nos parafusos sextavados de 1/2" da JOMARCA foi encontrado torque de 50 N.m, enquanto que o especificado pela Tabela 1 de torques para parafusos série polegada rosca normal é de 65 N.m. Portanto, os valores não ficaram dentro da faixa de tolerância do torquímetro da Gedore que é de 3\%. Esse seria um caso semelhante ao parafuso de 3/8" da mesma marca.

De acordo com os dados obtidos, foram verificados que o fabricante BELENUS foi o que obteve melhor desempenho baseado nos dados adquiridos nos testes, possuindo maior coerência entre os valores informados na tabela e os valores mostrados no ensaio.

Após a aplicação do torque elástico foi verificado se as porcas deslizavam no parafuso e ambos obtiveram resultados positivos.

A tensão de escoamento do parafuso de 3/8" da BELENUS foi menor do que o parafuso da JOMARCA, enquanto o parafuso de $1 / 2$ " da BELENUS iniciou a fase de escoamento com um torque maior do que o parafuso da JOMARCA. O torque máximo do parafuso de $3 / 8$ " da BELENUS foi praticamente igual à da JOMARCA, enquanto que o parafuso $1 / 2$ "' da BELENUS houve uma diferença significativa entre a fase de escoamento e onde ocorreu a ruptura.

\section{CONCLUSÃO}

A importância de se controlar a qualidade é diminuir e mitigar erros ocorridos durante o processo de produção, por meio da implantação de regras e normas. O controle de qualidade, como o próprio nome já diz, serve para controlar a qualidade e manter o padrão de excelência das empresas.

Foi realizado o ensaio em todos os parafusos para observar se realmente os dados fornecidos pelo fabricante são reais e qual o fabricante seria o mais confiável. Nos ensaios 
realizados foram observados o limite de proporcionalidade, o escoamento, o momento máximo e o momento de ruptura. Os gráficos de torque e distorção nos parafusos ensaiados, lembrando que as curvas foram geradas para cada modelo de parafuso dos dois fabricantes, pois os resultados foram semelhantes.

Pode-se concluir que a marca BELENUS obteve resultados mais satisfatórios a partir dos dados obtidos pelo gráfico. Além dos fatores já mencionados na Análise de Resultados dos parafusos da marca JOMARCA, como processo de caldeiraria, usinagem, falha no projeto do produto, verificou-se que as informações fornecidas pelo fabricante não condiziam com o que fora observado durante a análise, pois os parafusos foram capazes de suportar uma carga muito superior à mencionada pelo fabricante.

\section{REFERÊNCIAS BIBLIOGRÁFICAS}

ALLEN, E.; LANO, J. Fundamentos da Engenharia de Edificações - Materiais e Métodos. Porto Alegre: Bookman, 2013.

ANDRADE, R. O. B.; AMBONI, N. Estratégias de Gestão: processos e funções do administrador. Rio de Janeiro: Elsevier Editora Ltda., 2010.

BEER, F. Mecânica dos Materiais. São Paulo: Bookman, 2015.

CARDOSO, C. M. Z. Manual do controle da Qualidade de matérias-primas vegetais para farmácia magistral. São Paulo: Pharmabooks, 2009.

DOWLING, N. Comportamento Mecânico dos Materiais. São Paulo: ELSEVIER, 2017.

DUARTE, G. Dicionário de Administração. São Paulo: Kindle, 2015.

ESTRELA, C. Metodologia Científica: Ciência, ensino e pesquisa. Porto Alegre: Artes Médicas, 2018.

ISO 9001:2015 - Sistemas de Gestão da Qualidade - Requisitos. Disponível em; https://www.abntcatalogo.com.br/norma.aspx?ID=345041. Acesso em 10 de maio de 2018.

JUNIOR, I. M. Gestão da Qualidade e Processos. Rio de Janeiro: Copyright, 2015.

MOMENTOS TORÇORES (Torques). Disponível em: https://www.ciser.com.br/download/informacoes-tecnicas Acesso em 10 de maio de 2018.

SELEME, R. Controle da Qualidade as ferramentas essenciais. São Paulo: IBPEX, 2008.

UENO, J.T. Gestão da Qualidade. São Paulo: SENAC, 2017.

VERRI, L. B. A Evolução Real da Qualidade e sua Hipocrisia Administrativa. Rio de Janeiro: Copyright, 2013. 